\title{
Comunicação científica digital em Libras
}

\author{
Digital scientific communication in Libras
}

\author{
Lucas Pazoline da Silva Ferreira ${ }^{1}$ \\ Lorena Gomes Freitas de Castro ${ }^{2}$
}

\begin{abstract}
Resumo: A incorporação de hipermídia nas publicações científicas contemporâneas apresentase como uma possibilidade de refletirmos sobre uma comunicação científica inclusiva e acessível para os pesquisadores surdos. Assim, nosso estudo tem como objetivo analisar propostas nacionais de comunicação científica periódica em Libras (Língua Brasileira de Sinais). Para isso, catalogamos e examinamos diferentes materiais, a saber: documentos oficiais que orientam a produção e divulgação de conteúdo em Libras; e normas ou artigos de periódicos científicos que contemplam a publicação em Libras. Fundamentamos nosso trabalho nos estudos de Marques e Oliveira (2012), Braga (2013) e Ferreira (2014; 2017), dentre outros pesquisadores. Os resultados das análises apontam para a incipiência de orientações e normas oficiais de elaboração de conteúdo científico em Libras videossinalizada, em âmbito nacional. Além disso, há um quantitativo ínfimo de periódicos científicos que oferecem seus relatos de pesquisa acessíveis à comunidade surda. Sendo assim, apresentamos uma proposta de reestruturação e criação de periódicos bilíngues (Português-Libras ou Libras-Português), atrelada a um conjunto de características técnicas mínimas para produções videossinalizadas.
\end{abstract}

Palavras-chave: Língua Brasileira de Sinais. Comunicação Digital. Produção Científica. Hipermídia.

\begin{abstract}
The incorporation of hypermedia in contemporary scientific publications presents itself as a possibility to reflect on an inclusive and accessible scientific communication for deaf researchers. Thus, our study aims to analyze national proposals for periodic scientific communication in Libras (Brazilian Sign Language). We have catalogued and examined different materials: official documents that guide the production and dissemination of content in Libras and texts from scientific journals that include publication in Libras. This work was fundamented by the studies of Marques and Oliveira (2012), Braga (2013) and Ferreira (2014; 2017), among other researchers. The results of the analyzes point to the incipience of official guidelines and norms for the elaboration of scientific content in video-signaled Libras, nationwide. In addition, there is a very few amount of scientific journals that offers their research reports in accessible ways to the deaf community. Therefore, we present a proposal for restructuring and creating bilingual periodicals (Portuguese-Libras or Libras-Portuguese), linked to a set of minimum technical characteristics for video-signaled productions.
\end{abstract}

Keywords: Brazilian Sign Language. Digital communication. Scientific Production. Hypermedia.

\footnotetext{
1 Universidade Federal de Sergipe, Departamento de Letras Vernáculas, São Cristóvão, SE, Brasil. prof.lucaspazoline@gmail.com.

${ }^{2}$ Universidade Federal de Sergipe, Programa de Pós-Graduação em Letras, São Cristóvão, SE, Brasil. lorenna.gfc@gmail.com.
} 


\section{Introdução}

Podemos afirmar que uma das características inerentes ao fazer científico contemporâneo é a integração de diferentes tecnologias computacionais em vários setores da atividade de pesquisa, inclusive na comunicação formal entre pesquisadores, através de redes sociais especializadas, eventos e periódicos, exclusivamente digitais. No caso das revistas científicas, por exemplo, o uso de diferentes modalidades linguísticas e ferramentas (texto escrito, áudio, vídeo, recursos de navegação, entre outros) já pode ser verificado na composição de artigos científicos, de modo a atender demandas de determinadas áreas de estudo para publicação de conteúdo específico ${ }^{3}$.

Essa incorporação de hipermídia em relatos de pesquisa, de acordo com Ferreira (2014; 2017), projeta-se como uma nova modalidade do artigo científico, o ciberartigo. Entre as aplicações desse conceito, também está a possibilidade de refletirmos sobre uma comunicação científica inclusiva e acessível que, através do uso de aparatos e sistemas tecnológico-digitais, busca atender às necessidades de todos os envolvidos na prática científica, sem exceção. Diante disso, nosso estudo tem como objetivo analisar propostas nacionais de comunicação científica periódica em Libras (Língua Brasileira de Sinais) ${ }^{4}$.

Inicialmente, buscamos mapear os periódicos que viabilizam a integração de conteúdo em Libras aos artigos. Em seguida, examinamos o processo de composição, submissão e publicação dos textos, de modo a identificar as normas ou orientações existentes para produção de conteúdo em Libras. Por fim, contemplando documentos oficiais e parâmetros estabelecidos por instituições nacionais voltadas aos usuários de Libras, propomos mecanismos que viabilizem a participação da comunidade acadêmica surda e não surda em práticas comunicativas adequadas à modalidade linguística da Libras sinalizada, ou seja, visualespacial.

Acreditamos, conforme Braga (2013, p. 9), que o uso dos ambientes digitais pode contribuir para um "processo de imersão dos sujeitos em práticas comunicativas significativas". Sendo assim, estamos diante de um ambiente de potencialidades, desafios e soluções para a elaboração e execução de estratégias que permitam a universalização do acesso ao conhecimento científico, orientada por princípios de equidade e respeito à diversidade, especialmente orientada ao periodismo científico em Libras.

\footnotetext{
${ }^{3}$ Ver em: https://www.elsevier.com/connect/designing-the-article-of-the-future. Acesso em: 02 dez. 2021.

${ }^{4}$ A Libras sobre a qual tratamos aqui é a videossinalizada. Essa terminologia está de acordo com a proposta elaborada por Silva (2019), na qual, o pesquisador descreve, em termos de prática social, os usos das seguintes modalidades: Libras, Libras videossinalizada, Libras escrita (signwriting), Libras avatar (software 3D) e Libras tátil.
} 


\section{Considerações sobre o conceito de ciberartigo}

Ao observarmos o desenvolvimento e a expansão das tecnologias digitais nas últimas décadas, bem como sua incorporação nas diversas esferas de atividade humana, podemos afirmar que houve certa "digitalização" de vários setores sociais, inclusive no âmbito das práticas de comunicação científica. Assim, vislumbramos mudanças significativas, por exemplo, na composição de textos representativos de gêneros tradicionais na academia, como o artigo científico.

Em uma perspectiva otimista acerca das potencialidades do uso de ambientes digitais para comunicação científica (BOLTER, 1991; LANDOW, 1992; LANHAM, 1994; GROSS; HARMON; REIDY, 2002), podemos destacar o uso de multimídia e de hiperlinks, a integração a bases de dados online, a flexibilidade de atualização de conteúdo, as ferramentas de navegação e os layouts personalizados como algumas opções que podem ser exploradas na composição de artigos.

Por outro lado, Owen (2005) ressalta que essas características hipermidiáticas podem ser incorporadas aos relatos de pesquisa desde que sejam consideradas questões econômicas, técnicas e institucionais, bem como haja aceitação e uso adequado de formatos digitais por aqueles envolvidos nas atividades de produção e comunicação científica. Em relação aos periódicos na área de Letras, Linguística e Artes, Marcuschi (2001, p. 90) destaca a necessidade de serem construídas "revistas eletrônicas com características hipertextuais" no lugar das réplicas eletrônicas do impresso.

Como ponto de partida, as primeiras experiências com periódicos exclusivamente digitais ocorrem no fim da década de 1980, com a publicação da New horizons in adult education e do EJournal ${ }^{5}$ (OWEN, 2005). Como não havia tantos modelos a seguir para o desenvolvimento de um periódico eletrônico em um contexto acadêmico, as propostas ainda se mantinham tímidas quanto à libertação dos modelos impressos.

Em âmbito nacional, Ferreira $(2014 ; 2017)$ reconhece a existência de uma conjuntura sociotécnica capaz de sustentar os chamados "ciberartigos", ou seja, práticas comunicativas científicas hipermidiáticas que extrapolam os limites físicos e conceituais da mídia impressa na composição de um relato de pesquisa. Segundo Ferreira (2014, p. 102), considera-se ciberartigo "um gênero emergente na Web [...] que se caracteriza pela integração de diferentes linguagens e ferramentas, em um modelo específico de escrita e leitura, somente possível através das tecnologias digitais".

\footnotetext{
${ }^{5}$ Ver em http://www.nova.edu/ aed/horizons/vol1n1 e https://link.springer.com/chapter/10.1007\%2F1-40205340-1_1. Acesso em: 02 dez. 2021.
} 
Essa arquitetura hipertextual analisada pode ser exemplificada através de propostas experimentais para o uso de hipermídia nos relatos científicos, a saber: os periódicos Kairos: A Journal of Rhetoric, Technology, and Pedagogy, Journal for Artistic Research (JAR) e Journal of Visualized Experiments (Jove); e os sistemas Article of the Future e Vega-Academic Publish System (FERREIRA, 2014; 2017). Em estudo mais recente, Ferreira et al (2021) apresentam alguns exemplares de periódicos e publicações com essas potencialidades do meio digital.

Portanto, diante da possibilidade de uso de hipermídia na comunicação científica periódica, buscamos identificar, em território nacional, uma perspectiva inclusiva e acessível direcionada às pessoas surdas sinalizantes da Libras ${ }^{6}$, por meio dos ciberartigos. Na próxima seção, descrevemos as etapas metodológicas para realização deste estudo.

\section{Escolhas metodológicas: coleta e seleção dos dados}

O percurso metodológico adotado para cumprir nossos objetivos de pesquisa envolve a catalogação e a análise de diferentes materiais, a saber: 1) documentos oficiais nacionais que normatizam ou trazem orientações para a produção e divulgação de conteúdo em Libras nas mais diversas esferas comunicativas; 2) documentos disponibilizados pelo Instituto Nacional de Educação de Surdos (INES), centro de referência na área da surdez no Brasil; 3 ) periódicos científicos direcionados à publicação em Libras (FERREIRA et al, 2021). Embora a comunicação científica periódica seja o foco do nosso estudo, o exame de documentos relacionados a práticas comunicativas mais gerais em Libras se faz necessário na medida em que serve de base para analisar o que ocorre em cada periódico.

Inicialmente, a identificação de parâmetros oficiais e nacionais para elaboração de conteúdo em Libras considerou analisar leis e decretos governamentais relacionados ao uso dessa língua em diversos setores sociais, bem como mapear normatizações para a elaboração de materiais para surdos através da Associação Brasileira de Normas Técnicas (ABNT), especialmente no que se refere a normas para comunicação científica. Nesse sentido, destacamos a Lei $n^{\circ}$ 10.436/2002, o Decreto Federal nº 5.626/2005 e a NBR 15290:2016 como pontos de partida para nosso estudo.

Em seguida, continuando a análise documental, recorremos aos conteúdos disponibilizados pelo INES, visto que se trata de uma das principais instituições nacionais de

\footnotetext{
${ }^{6}$ Conforme Quadros (2019), o termo “sinalizantes" se refere àqueles, no Brasil, que utilizam a Libras em toda sua extensão territorial, principalmente, considerando os espaços urbanos e a interação entre as comunidades surdas. Nas palavras da pesquisadora, "os sinalizantes são normalmente surdos, mas também podem ser ouvintes" (QUADROS, 2019, p. 34).
} 
produção e capacitação educacional da comunidade surda. Esse órgão do Ministério da Educação possui uma jornada que começou durante o governo imperial, por volta do século XIX, quando se chamava Colégio Nacional para Surdos-Mudos. Desde sua inauguração, teve alterações no nome e atendeu não somente brasileiros, mas também alunos do exterior, uma vez que é a instituição mais antiga que promove a educação de surdos em território nacional e para países próximos.

De modo específico, por meio da plataforma online TV INES e do site da instituição, que inclui conteúdo produzido pelo Departamento de Ensino Superior (DESU-INES), conseguimos examinar o Manual para Normalização de Trabalhos Monográficos em Libras e Língua Portuguesa. Além disso, observamos os conteúdos em vídeo da TV INES, a fim de identificar parâmetros em uso para comunicação ou divulgação científica em Libras, como é o caso de características não normatizadas, mas recorrentes nas produções, por exemplo.

No que se refere à busca por periódicos que publicam conteúdo científico em Libras, foi realizada uma triagem ${ }^{7}$ a partir da análise daqueles registrados na Plataforma Sucupira (https://sucupira.capes.gov.br), especificamente em consulta à base de dados do Qualis Periódicos. Diante da grande quantidade de títulos, nosso estudo se limitou à classificação nas áreas de "Linguística e Literatura", e "Artes”, do quadriênio de avaliação 2013-2016". Sendo assim, foram selecionados apenas títulos nacionais, recomendados e avaliados por órgãos de pesquisa e desenvolvimento científico, nos quais se verificasse a publicação de relatos de pesquisa em Libras ${ }^{9}$. Aliás, como um dos critérios de seleção ou exclusão de periódicos, verificamos nas seções "foco/escopo" e nas "regras de submissão" a existência de um engajamento para uso de hipermídia em artigos científicos, direcionado à comunidade surda no que diz respeito à acessibilidade linguística. A seguir, apresentamos as observações acerca dos documentos e periódicos.

\section{Análise documental e parâmetros gerais para Libras videossinalizada}

Nesta seção, apresentamos as análises de alguns documentos que trazem a Libras como meio de comunicação e expressão na promoção da acessibilidade, apontando (ou não) formas

\footnotetext{
${ }^{7}$ Os dados foram obtidos através de um estudo piloto sobre comunicação científica em hipermídia para formação de corpora, realizado através do Grupo de Estudos Filológicos em Sergipe (GEFES), em sua linha Autoria, Plágio e Escrita Acadêmica.

${ }^{8}$ A última avaliação (quadriênio 2016-2020) ainda não se encontra disponível no site do programa, embora circule em sites de periódicos uma avaliação preliminar não oficial.

9 Para complementar a busca por periódicos, foi realizada uma análise de alguns títulos específicos para a comunidade surda, sugeridos pela plataforma INES, mas que não constam na listagem da Plataforma Sucupira. Entretanto, não encontramos resultados satisfatórios, de acordo com nosso objetivo de pesquisa.
} 
de normatização de conteúdo para a modalidade videossinalizada. Reiteramos que as discussões aqui apresentadas não têm por objetivo estabelecer uma desqualificação dos documentos ou dos periódicos, mas evidenciar principalmente parâmetros que viabilizem a elaboração de conteúdo em Libras para contextos formais de interação, como a comunicação científica.

Como ponto de partida para nossas discussões, destacamos a Lei $\mathrm{n}^{\circ} 10.436$, de 24 de abril de 2002, que reconhece a Libras como meio legal para a comunicação da comunidade surda, e o Decreto ${ }^{\circ}$ 5.626, de 22 de dezembro de 2005, que regulamenta a Lei supracitada e dispõe sobre várias outras questões, a saber: a Libras enquanto disciplina curricular, a formação de professores e de profissionais intérpretes, a difusão da língua, a acessibilidade, dentre outras.

Esses documentos constituem um marco muito importante no que alude à percepção legal da Libras, uma vez que "esse reconhecimento oficial, ao lado de seu status linguístico, é uma conquista dos movimentos sociais encabeçados pelas lideranças surdas” (QUADROS, 2019, p. 20, grifo da autora). Entretanto, não há nesses documentos quaisquer orientações ou normas sobre como estruturar, organizar e registrar os materiais em Libras videossinalizada, objeto do nosso estudo. De fato, encontramos no Art. 24 do Decreto ${ }^{\circ} 5.626$ uma referência à disponibilização da janela com intérprete na modalidade de educação a distância.

Quadro 1 - Diretrizes para a janela de LIBRAS, conforme NBR 15290:2016

\section{Características gerais para geração da janela de LIBRAS}

a) janela de LIBRAS incorporada ao vídeo original: o vídeo do programa já contém a janela de LIBRAS sobreposta ao conteúdo original, inserida pelo próprio produtor do conteúdo, de forma que o telespectador não tenha controle sobre a manipulação desta janela, sendo que pode conter um intérprete humano ou virtual, conforme ABNT NBR 15610-3 e a ABNT NBR 15604

b) intérprete virtual (modelo tridimensional computadorizado): é a representação gráfica do responsável por exibir a tradução, de forma que o telespectador tenha controle sobre a manipulação desta janela, conforme ABNT NBR 156103 e ABNT NBR 15604

c) vídeo secundário: um segundo fluxo elementar de vídeo é enviado em conjunto com o vídeo da programação principal. O vídeo secundário exibirá apenas um intérprete de LIBRAS realizando a tradução, que poderá ser ou não um intérprete virtual, de forma que o telespectador tenha controle sobre a manipulação desta janela, conforme ABNT NBR 15610-3 e ABNT NBR 15604

\section{Características para a exibição da janela de LIBRAS}

d) os contrastes devem ser nítidos, quer em cores, quer em preto e branco

e) deve haver contraste entre o plano de fundo e os elementos do intérprete

\section{Características da transmissão}

f) Deve estar de acordo com as diretrizes para a transmissão dos recursos de acessibilidade (Seção 7, NBR 15290) Fonte: ABNT (2016a, p. 11).

No que diz respeito à existência de normas oficiais de âmbito nacional, a ABNT prescreve, através da NBR 15290:2016 ${ }^{10}$ (ver Quadro 1), alguns critérios de organização de conteúdo em Libras direcionados à acessibilidade em comunicação televisiva. Em sua seção 6

${ }^{10}$ A NBR 15290:2016 é a segunda edição. A $1^{a}$ edição dessa NBR foi publicada no ano de 2005 e traz algumas diretrizes gerais sobre a janela de Libras no que diz respeito ao espaço/estúdio, janela, recorte, requisitos para a interpretação e visualização. 
e respectivos subitens $\left(6,6.1,6.2\right.$ e 6.3), o documento prevê diretrizes para a janela de Libras ${ }^{11}$ de forma sobreposta ou por vídeo secundário, contendo intérprete humano ou virtual, bem como contrastes de exibição nítidos entre o plano de fundo e as pessoas que interpretam, em cores ou não (ABNT, 2016). Quanto à comunicação científica, não são apresentadas, no entanto, normas para organização, elaboração e apresentação textual em Libras, tal qual é prescrito para os textos em português (margens, citações, referências, espaçamento e outros aspectos).

Já a NBR 15610-3, mencionada pela NBR 15290:2016, é uma normativa organizada por uma Comissão de Estudo Especial, que circulou em consulta nacional e versa especificamente sobre a Libras. Como observado, o documento "apresenta uma proposta de protocolo de transmissão de conteúdos em Língua de Sinais (LIBRAS) para o Sistema Brasileiro de Televisão Digital Terrestre (SBTVD)" (ABNT, 2016b, p. 1), em duas estratégias principais para transmissão compatível (ver Quadro 2). As definições e orientações previstas na NBR 15610-3 são bastante técnicas, não apresentando, por sua vez, diretrizes a respeito da organização textual, normas alusivas a seções textuais, indicações de vestuário e outros.

Quadro 2 - Diretrizes para transmissão de um vídeo em LIBRAS, conforme NBR 15610-3

a) transmissão de um vídeo com uma sequência em LIBRAS pela estação de TV como um fluxo elementar (Eleentary Stream - ES) de vídeo secundário. Nesse caso, o vídeo de LIBRAS pode ser produzido com intérpretes humanos ou gerado automaticamente usando agentes animados virtuais (avatares-3D) na estação emissora de TV. [...]

b) a transmissão sucessiva de um conjunto de glosas (representação textual de sinais da LIBRAS) codificado ao longo do tempo. As glosas (sinais de LIBRAS codificados em formato texto) são transmitidas e posteriormente decodificadas e apresentadas no receptor por meio do mapeamento destas em representação visual feita com base em um dicionário. [...]

Fonte: ABNT (2016b, p. 7).

Continuando nossa análise de normas ou parâmetros para comunicação científica através de Libras videossinalizada, além da ABNT, o INES nos oferece o Manual para Normalização de Trabalhos Monográficos em Libras e Língua Portuguesa, documento produzido em 2015 pelo Departamento de Ensino Superior (DESU-INES), que tem por objetivo a educação bilíngue de surdos. Além disso, as orientações e normas que constam no Manual “foram baseadas em propostas que vêm sendo utilizadas na Gallaudet University, na Revista Brasileira de Vídeo Registro de Língua de Sinais Brasileira (UFSC), incluindo artigos e dissertações de pesquisadores surdos" (DESU-INES, 2015, p. 11).

\footnotetext{
${ }^{11}$ A janela de Libras é um espaço onde deve aparecer um vídeo com informações interpretadas do português para Libras.
} 
Sendo assim, constatamos que a monografia em Libras "requer roteirização, direção e edição de vídeo com rigores à esfera formal e científica, ou seja, um trabalho efetivamente acadêmico como requisito de certificação em Pedagogo" (DESU-INES, 2015, p. 12). No que alude à divulgação em língua portuguesa, o documento segue as normas da ABNT e orienta que as indicações do manual devem ser utilizadas para quaisquer trabalhos de cunho acadêmico.

Na instância da divulgação digital, destaca-se a TV INES ${ }^{12}$, primeira webTV brasileira com programação bilíngue Libras/Português. A plataforma conta com recursos de legenda e locução a fim de tornar toda a sua programação acessível ao público, além de possibilitar o acesso aos materiais via aplicativo. Além disso, há uma variedade de conteúdos que contemplam áreas da educação, entretenimento, jornalismo, filmes, documentários, entre outros. Desse modo, os vídeos podem ter duração de aproximadamente um minuto até pouco mais de uma hora, a depender da área de produção e/ou do gênero associado ao conteúdo.

Devido a essa variedade de informações e propostas acessíveis ao público, não observamos uma padronização específica na apresentação do conteúdo em Libras quanto ao uso do plano de fundo com/sem detalhes, contrastes, roupas, uso do espaço para sinalização, entre outros elementos que são mencionados no próprio manual do DESU/INES para uma comunicação adequada em Libras videossinalizada.

No entanto, apesar da não identificação de normas específicas, percebemos as seguintes características gerais: 1) os sinalizantes utilizam roupas compostas (nem curtas, nem compridas), geralmente de cores lisas; 2) eles estão posicionados a uma distância do plano de fundo/ambiente, o que possibilita visualizar toda a sinalização sem prejuízos à compreensão textual; 3) e não são utilizados recursos visuais que causem ruídos de comunicação, os quais comprometem a leitura da língua e das expressões não manuais ${ }^{13}$ nos contextos mencionados.

Além do material produzido pela própria TV INES, a plataforma também exibe produções enviadas pelo público, desde que sigam as instruções básicas de submissão ${ }^{14}$. Um desses parâmetros está relacionado à produção do conteúdo em Libras, a saber: “o vídeo pode ser feito por celular, filmadora, câmeras caseiras e deve ter a melhor qualidade de som e imagem possível”. Embora não haja detalhamento técnico específico para formato de tela ou outros

\footnotetext{
${ }^{12}$ Apesar de ter sido criada pela parceria entre o Instituto Nacional de Educação de Surdos (INES) e a Associação de Comunicação Educativa Roquette Pinto (ACERP), a TV INES teve sua programação temporariamente interrompida por questões de descumprimento contratuais. Ver mais em: https://www.ines.gov.br/component/content/article?id=1093. Acesso em: 02 dez. 2021.

13 "As expressões não-manuais (movimento da face, dos olhos, da cabeça ou do tronco) prestam-se a dois papéis nas línguas de sinais: marcação de construções sintáticas e diferenciação de itens lexicais" (QUADROS; KARNOPP, 2004, p. 60).

${ }^{14}$ Ver em http://tvines.org.br/?page id=31. Acesso em: 02 dez. 2021.
} 
parâmetros de mídia, percebemos uma preocupação mínima com a qualidade da gravação a ser enviada à TV INES, a qual poderá aprovar ou não a publicação do material em sua plataforma digital. Por sua vez, a fim de ampliar nossa investigação para além dos documentos e projetos governamentais apresentados até o momento, discutimos, a seguir, sobre a Libras videossinalizada nos periódicos científicos nacionais.

\section{A Libras videossinalizada em periódicos de Letras, Linguística e Artes}

Com base na análise dos periódicos registrados na Plataforma Sucupira para as áreas de "Linguística e Literatura" e "Artes”, do quadriênio de avaliação 2013-2016, foram identificados três títulos nacionais em que há um engajamento para elaboração e publicação de conteúdo direcionado à comunidade surda: i) Revista Brasileira de Tradução Visual (RBTV) ${ }^{15}$; ii) Camine - Caminhos da Educação ${ }^{16}$; iii) Revista Brasileira de Vídeo-Registro em Libras $(\mathrm{RBVR})^{17}$.

A Revista Brasileira de Tradução Visual foi inaugurada em 2009, na Universidade Federal de Pernambuco, sob a coordenação dos pesquisadores Francisco José de Lima, Rosângela Aparecida Ferreira Lima e Carlos Antônio Fontenele Mourão. O periódico é direcionado às seguintes áreas: Pesquisa e Desenvolvimento; Cultura e Direito; Letras/Linguística e Educação; Psicologia e Trabalho. Particularmente, trata-se de uma publicação destinada a pesquisas sobre acessibilidade comunicacional, com temas que versam sobre audiodescrição, legendagem, closed-captioning, entre outros.

Constam, entre as publicações deste periódico, textos representativos de diversos gêneros, desde artigos originais e de revisão, perpassando por traduções, ensaios e resenhas, até propostas específicas, como, por exemplo, a "Imagem, ciência e tecnologia" (análises de imagens, equipamentos e softwares), e o Artigo Especial (sem classificação específica, mas relevante). Cumpre destacar que alguns artigos apresentam áudio e vídeo em sua composição, além de hiperlinks, mas a revista não oferece parâmetros ou normas para o uso de hipermídia nos textos.

Ainda que a RBTV se destaque na acessibilidade promovida por audiodescrição direcionada à comunidade cega ou com deficiência visual, ela também se destaca para a comunidade surda, que pode ler/enviar artigos em Libras. Para isso, além dos itens de

\footnotetext{
${ }^{15}$ Disponível em: https://audiodescriptionworldwide.com/revista-brasileira-de-traducao-visual/. Acesso em: 02 dez. 2021.

${ }^{16}$ Disponível em: https://ojs.franca.unesp.br/index.php/caminhos. Acesso em: 02 dez. 2021.

${ }^{17}$ Disponível em: https://revistabrasileiravrlibras.paginas.ufsc.br/. Acesso em: 02 dez. 2021.
} 
diagramação relacionados à extensão de organização do texto escrito, o periódico apresenta duas normativas para a submissão de trabalhos em Libras (modalidade visual-espacial e videossinalizada), a saber: a) "Os artigos em Libras deverão seguir padrões acadêmicos de apresentação, trazendo resumo em Libras e em português"; b) “Os artigos em Libras deverão ser registrados com boa imagem, iluminação e demais quesitos necessários para uma boa leitura no computador". Entretanto, os textos em Libras publicados pela RBTV não estão mais disponíveis $^{18}$, uma vez que os links atualmente não apontam para seus respectivos arquivos (vídeos).

Outro ponto de destaque da RBTV é o fato de a mesma estabelecer pontos de contato com a sociedade em geral através de seções destinadas a relatos de experiência enviados pela comunidade não acadêmica. Sobre o uso de hipermídia nos textos, alguns artigos apresentam áudio e vídeo em sua composição, além de hiperlinks. Enfim, ainda que apresente potencial inclusivo, desde 2015, o periódico se encontra sem novos volumes.

Em seguida, no âmbito das discussões sobre a implementação de políticas educacionais, a Camine - Caminhos da Educação publica ensaios, resenhas, entrevistas e artigos científicos inéditos de carácter teórico, bibliográfico e empírico, que abordam temas sobre a democratização do ensino e a elaboração/análise de políticas públicas para a educação. Em suas edições semestrais, a Camine representa, desde 2009, os esforços de pesquisadores nacionais e internacionais, especialmente da Faculdade de Ciências Humanas e Sociais, da Universidade Estadual Paulista - Campus de Franca, em São Paulo.

No que se refere aos textos publicados, o periódico promove a acessibilidade do seu conteúdo a pessoas com deficiências diversas através de algumas estratégias que envolvem a integração de diferentes linguagens por meio da web, a saber: resumos videossinalizados com intérprete humano ou virtual, com ou sem áudio associado; e resumos ou textos completos em audiodescrição. A composição dessa proposta assistiva está sob a responsabilidade da equipe editorial, uma vez que não foram publicadas regras para elaboração e submissão desse tipo de material em áudio ou vídeo por parte dos autores.

Por último, direcionada principalmente à comunidade surda, a Revista Brasileira de Vídeo-Registro em Libras - (RBVR) é uma publicação da Universidade Federal de Santa

\footnotetext{
18 Os textos em Libras indisponíveis são os seguintes: i) "Direitos Linguísticos dos Surdos", verificável em http://audiodescriptionworldwide.com/associados-da-inclusao/rbtv/direitos-linguisticos-dos-surdos/;

"Emancipação de Sinais em Libras: um Estudo acerca dos Classificadores Matemáticos", verificável em http://audiodescriptionworldwide.com/associados-da-inclusao/rbtv/emancipacao-de-sinais-em-Libras-umestudo-acerca-dos-classificadores-matematicos/; iii) "E-acessibilidade para surdos", verificável em http://audiodescriptionworldwide.com/associados-da-inclusao/rbtv/e-acessibilidade-para-surdos-2/. Acesso em: 02 dez. 2021.
} 
Catarina (UFSC), por meio do Grupo de Pesquisa em Vídeo Registro em Libras, pioneiro no estabelecimento de normas e orientações para a submissão de textos científicos em Libras (ver Anexo). Com seu primeiro volume disponibilizado em 2013, os artigos publicados não seguem as regras de extensão e organização dos modelos impressos, visto que o material é publicado exclusivamente em vídeo, sem tradução complementar para a língua portuguesa nas modalidades escrita ou oral. Além disso, a RBVR apresenta a maior parte das suas informações em Libras, como se pode ver no editorial, na apresentação da revista, nas normas para submissão, entre outras orientações.

Sob a coordenação dos professores Rodrigo Rosso Marques, Rodrigo Custódio da Silva e Alexandre Bet da Rosa, todos da UFSC, a RBVR se estabelece como uma das principais precursoras nacionais na consolidação de uma comunicação científico-acadêmica direcionada a pessoas surdas, ainda que não possua regularidade na publicação das edições. Além disso, cumpre destacar que os pesquisadores se fundamentaram nas NBRs 6022, 6023, 6028 e 10520, que são normatizações consolidadas sobre a elaboração de referências, resumo e citações.

Pensando na possibilidade de contribuir para a melhoria da qualidade da educação das pessoas surdas no que envolve a questão da escrita, o "Projeto de Pesquisa VídeoRegistro em Libras: registros e possibilidades" vem chamar a atenção não para a criação de uma forma de registro inovadora, mas perceber uma escrita presente, disponível a todas as pessoas surdas. Ela não precisa ser aprendida, ela está em cada falante de Língua de Sinais, e necessita apenas ser reconhecida enquanto tal e ser sistematizada na sua forma de representação. (MARQUES; OLIVEIRA, 2012, p. 1)

Embora estejamos diante de um quantitativo ínfimo de periódicos científicos que oferecem seus relatos de pesquisa acessíveis à comunidade surda, observamos que há parâmetros consistentes tanto para a elaboração de conteúdo em Libras videossinalizada, quanto para o uso de tecnologias digitais que permitam uma comunicação científica com equidade e respeito à diversidade. Diante disso, na próxima seção, incentivamos a acessibilidade das pessoas surdas (Libras videossinalizada) e não surdas (texto escrito complementar em português e/ou locução), contemplando uma hibridização de linguagens e ferramentas que não apenas considere as modalidades oral e escrita da língua portuguesa, mas também a modalidade visual-espacial da Libras.

\section{Possíveis parâmetros para uma comunicação científica em Libras}

A análise de normativas nacionais, de parâmetros institucionais e de ações diversificadas no âmbito da comunicação científica em Libras por alguns periódicos científicos permite-nos a proposição de mecanismos que possam viabilizar uma participação mais efetiva 
da comunidade acadêmico-científica surda em espaços de produção e popularização da ciência. Em outras palavras, consideramos importante estabelecer algum parâmetro prototípico nacional no intuito de engajar editores científicos e a comunidade de pesquisadores não surdos e surdos para uma publicação cada vez mais democrática e acessível. Enfim, trata-se de uma iniciativa que tenta explorar/incentivar práticas comunicativas adequadas à modalidade linguística da Libras sinalizada.

Diante do que foi identificado nas análises, nossa proposta está pautada em duas vertentes, a saber: a reestruturação e a criação. Em primeiro lugar, a reestruturação se estabelece como a integração gradativa de conteúdo videossinalizado em periódicos digitais tradicionalmente constituídos por modelos de comunicação baseados nas línguas orais. Por sua vez, a criação pode ser entendida como a construção de periódicos digitais cuja publicação principal ocorre em Libras, com a integração de material complementar (escrito ou oralizado) nas línguas orais-auditivas.

Considerando o quantitativo inexpressivo de periódicos exclusivamente em Libras, a reestruturação torna-se, num primeiro momento, uma alternativa mais viável, uma vez que esse movimento já acontece em diferentes níveis no periodismo brasileiro. O Quadro 3 apresenta uma parametrização fundamentada nas possibilidades e ações identificadas nas diferentes propostas para comunicação científica em Libras discutidas anteriormente.

Quadro 3 - Níveis de reestruturação para periódicos não-videossinalizantes

\begin{tabular}{|l|c|c|c|c|c|}
\hline \multirow{2}{*}{\multicolumn{2}{c|}{ CARA CTERÍsTICAS }} & \multicolumn{5}{|c|}{ NíVEIS } \\
\cline { 2 - 6 } & $\mathbf{1}$ & $\mathbf{2}$ & $\mathbf{3}$ & $\mathbf{4}$ & $\mathbf{5}$ \\
\hline Tradução automática (intérprete virtual) & $\mathrm{x}$ & $\mathrm{x}$ & $\mathrm{x}$ & $\mathrm{x}$ & $\mathrm{x}$ \\
\hline Resumo videossinalizado & & $\mathrm{x}$ & $\mathrm{x}$ & $\mathrm{x}$ & $\mathrm{x}$ \\
\hline Chamada/Circular videossinalizada & & & $\mathrm{x}$ & $\mathrm{x}$ & $\mathrm{x}$ \\
\hline Publicação principal videossinalizada & & & & $\mathrm{x}$ & $\mathrm{x}$ \\
\hline Editores/pareceristas surdos ou bilíngues & & & & & $\mathrm{x}$ \\
\hline
\end{tabular}

Fonte: elaborado pelos autores (2021).

As características do Quadro 3 envolvem diferentes níveis de reestruturação dos periódicos, os quais se aglutinam para formar níveis cada vez mais avançados. O Nível 1 se refere à introdução de recursos de automação nos sistemas ou sites dos periódicos. Esses sistemas já existem (cf. VLibras, ProDeaf, Hand Talk, Rybená) e interpretam conteúdos digitais de Português para a Libras. Em seguida, o diferencial do Nível 2 é a publicação do resumo do 
artigo principal (escrito) em Libras videossinalizada. Esse material complementar pode ser elaborado pelo autor ou pela equipe da revista, como acontece no periódico Camine. Já o Nível 3 possui como característica principal tornar acessível à comunidade acadêmica surda as chamadas ou circulares de submissão de trabalhos. Desse modo, seria disponibilizada a esses pesquisadores mais uma ferramenta de acesso à informação.

Por conseguinte, os periódicos nos níveis 4 e 5 promoveriam um maior engajamento da comunidade surda, na medida em que há uma possibilidade de "agência"19 para além de uma mera recepção dos conteúdos. No Nível 4, ainda que haja publicações em língua oral-auditiva (modalidade escrita), o periódico estaria disposto a incorporar textos completos em Libras videossinalizada. Esses textos seriam representativos de gêneros que, em certa medida, possuem maior relevância na publicação científica, como artigos e ensaios acadêmicos. Por fim, o Nível 5 integraria todas as características dos níveis anteriores, acrescentando a participação de pesquisadores surdos ou intérpretes bilíngues (Português-Libras) na edição e/ou avaliação de volumes dos periódicos.

Quadro 4 - Características técnicas mínimas das produções videossinalizadas

\begin{tabular}{|l|l|}
\hline \multicolumn{1}{|c|}{ CARACTERÍSTICA } & \multicolumn{1}{c|}{ ESPECIFICAÇÕES } \\
\hline Resolução e espaço de sinalização & $\begin{array}{l}\text { Tela 16:9 (widescreen), com resolução Full HD 1920x1080 ou HD 1080x720, 29 } \\
\text { fps, em AVI ou MP4. }\end{array}$ \\
\hline $\begin{array}{l}\text { Ambiente de gravação } \\
\text { (Câmera fixa) }\end{array}$ & $\begin{array}{l}\text { O fundo precisa ser branco ou em contraste com o intérprete, sem ruídos visuais, } \\
\text { bem iluminado e sem sombras. }\end{array}$ \\
\hline Duração & Entre 20 e 40 minutos. \\
\hline Vestimenta & Blusas de manga curtas com cores únicas e lisas. \\
\hline Cores & $\begin{array}{l}\text { Contraste entre o plano de fundo e os elementos do intérprete. Sugestão: } \\
\text { apresentação de autores e seções (azul), texto (preta ou cinza). }\end{array}$ \\
\hline Conteúdo em Tela & $\begin{array}{l}\text { Títulos, nomes de autor e/ou tradutor, notas, referências, citações, tabelas, } \\
\text { imagens, legendas e outros elementos semelhantes. }\end{array}$ \\
\hline
\end{tabular}

Fonte: elaborado pelos autores (2021).

Diante da falta de uma normatização nacional semelhante ao que acontece com a ABNT para os trabalhos acadêmicos em português, o Quadro 4 apresenta um resumo das características técnicas mínimas para produções videossinalizadas direcionadas a periódicos ou a outros ambientes de comunicação científica online. As informações utilizadas para a construção do Quadro 4 tomam como base os parâmetros da RBVR e de outros periódicos e instituições apresentadas nas seções anteriores. O intuito é criar um caminho viável para autores e editores,

${ }^{19}$ Ver Bazerman (2006) e Miller (2009). 
considerando os problemas oriundos das condições políticas e de infraestrutura dos periódicos nacionais (PACKER, 2011).

Como dito anteriormente, outra vertente de atuação da nossa proposta é a criação de periódicos com publicação principal em Libras videossinalizada. Essa possibilidade estaria alinhada ao que já acontece na RBVR, podendo ser descrita como Nível 5 do quadro de reestruturação. Entretanto, uma vez que estamos promovendo uma publicação de caráter bilíngue (Libras-Português ou Português-Libras), a criação estaria subordinada à integração de material complementar em modalidade escrita (língua portuguesa, signwriting) ou em audiolegendagem ${ }^{20}$.

Nessa segunda vertente, os artigos, ensaios, resenhas e outros gêneros da comunicação científica em Libras estariam vinculados a resumos em português e até a uma tradução completa do texto videossinalizado. Como observado nas análises, esse movimento bilíngue se encontra efetivado no Manual de normatização do INES e mencionado nas propostas de publicação da RBTV e da RBVR. Assim, considerando diferentes formas para obtenção de um conhecimento acessível e compartilhado, acreditamos ser possível diminuir as distâncias entre pesquisadores surdos e não surdos.

\section{Considerações finais}

Como apresentado no decorrer deste artigo, refletimos sobre a comunicação científica digital em Libras, principalmente, considerando gêneros da esfera acadêmica e critérios para sua elaboração e organização, a partir da catalogação e da análise de diferentes materiais. Dentre os materiais, citamos documentos oficiais nacionais, institucionais e periódicos científicos direcionados à publicação em Libras. Estamos certos de que atingimos o objetivo de analisar propostas nacionais de comunicação científica em Libras e de que, através desse percurso, refletimos sobre uma comunicação científica inclusiva e acessível, mediada por sistemas tecnológico-digitais.

Nossa contribuição consiste, sobretudo, em descrever possíveis parâmetros para a comunicação científica digital em Libras, considerando características técnicas mínimas para a produção videossinalizada, bem como incentivando o acesso à/da comunidade científica surda principalmente. Alguns outros assuntos que poderiam ter sido desenvolvidos em nosso estudo ainda podem ser abordados em novos trabalhos, por exemplo, uma análise dos recursos e características padronizadas nos vídeos da plataforma da TV INES em função do gênero

\footnotetext{
${ }^{20}$ Não é foco deste trabalho, mas consideramos importante que uma atenção também seja dada à audiodescrição e a legendas descritivas.
} 
discursivo e da temática a que atendem, ou um exame dos efeitos da hibridização de linguagens através da audiodescrição e da videossinalização em um mesmo documento. Tais análises não foram realizadas por não constituírem o objetivo principal deste trabalho, embora sejam importantes.

Por fim, ratificamos que, ao evidenciar principalmente parâmetros que viabilizem a elaboração de conteúdo em Libras para contextos formais de interação, como a comunicação científica, reconhecemos a importância do uso efetivo das tecnologias digitais para contextos de acessibilidade e inclusão. Em nossa proposta, mostramos, então, a urgência de promover o registro de textos acadêmicos em Libras, bem como de expandir o acesso da comunidade surda em geral a materiais de estudo e pesquisa científica.

\section{Referências}

ASSOCIAÇÃO BRASILEIRA DE NORMAS TÉCNICAS. NBR 15.290: Acessibilidade em comunicação na televisão. Rio de Janeiro, 2016a.

ASSOCIAÇÃO BRASILEIRA DE NORMAS TÉCNICAS. NBR 15610-3: Televisão digital terrestre - Acessibilidade - Parte 3: Língua de Sinais (LIBRAS). Rio de Janeiro, 2016b.

BAZERMAN, C. Gênero, agência e escrita. São Paulo: Cortez, 2006.

BOLTER, J. D. Writing space: the computer, hypertext, and the history of writing. Hillsdale, NJ: Erlbaum, 1991.

BRAGA, D. B. Ambientes digitais: reflexões teóricas e práticas. São Paulo: Cortez, 2013.

BRASIL. Decreto $\mathbf{N}^{\mathbf{0}}$ 5.626, de 22 de dezembro de 2005. Regulamenta a Lei $\mathrm{n}^{\circ} 10.436$, de 24 de abril de 2002, que dispõe sobre a Língua Brasileira de Sinais - Libras, e o art. 18 da Lei $\mathrm{n}^{\circ}$ 10.098, de 19 de dezembro de 2000. 2005.

BRASIL. Lei 10.436, de 24 de abril de 2002. Dispõe sobre a Língua Brasileira de Sinais (Libras) e dá outras providências. 2002.

DESU/INES. Manual para normalização de trabalhos monográficos em Libras e língua portuguesa do DESU/INES. 2015. Disponível em:

http://www.ines.gov.br/images/desu/Manual-de-Monografia-em-Libras-e-LP-2015.pdf. Acesso em: 25 mar. 2021.

FERREIRA, L. P. da S. Ciencidade: o ciberartigo como gênero emergente na web. 2014. 118 f. Dissertação (Mestrado em Letras) - Programa de Pós-Graduação em Letras, Universidade Federal de Sergipe, 2014. Disponível em: https://ri.ufs.br/handle/riufs/5699. Acesso em: 30 jan. 2021.

FERREIRA, L. P. da S. Ciberartigo: um modelo de produção (hiper)textual na comunicação científica online. 2017. 277 f. Tese (Doutorado em Letras) - Programa de Pós-Graduação em 
Letras, Universidade Federal de Pernambuco, 2017. Disponível em: https://repositorio.ufpe.br/handle/123456789/29673. Acesso em: 30 jan. 2021.

FERREIRA, L. P. da S.; SOUZA, B. S. de; SILVA, L. O.; SILVA, J. L. D. da. Comunicação científica em hipermídia: um mapeamento de periódicos nas áreas de Letras, Linguística e Artes. Hipertextus Revista Digital, Recife, v. 23, n. 1, p. 4-16, 2021. Disponível em: https://periodicos.ufpe.br/revistas/hipertextus/article/view/250620. Acesso em: 02 dez. 2021.

GROSS, A.; HARMON, J.; REIDY, M. Communicating Science: The Scientific Article from the 17th Century to the Present. New York: Oxford University Press, 2002.

INSTITUTO NACIONAL DE EDUCAÇÃO DE SURDOS. Conheça o INES. Disponível em: https://www.ines.gov.br/conheca-o-ines. Acesso em: 27 mar. 2021.

LANDOW, G.P. Hypertext: the convergence of contemporary critical theory and technology. Baltimore, MD: Johns Hopkins University Press, 1992.

LANHAM, R. The electronic word: democracy, technology, and the arts. Chicago: University of Chicago Press, 1994.

MARCUSCHI, L. A. Revistas brasileiras em Letras e Lingüística. DELTA: Documentação de Estudos em Lingüística Teórica e Aplicada, v. 17, n. esp., p. 83-120, 2001. Disponível em: https://dx.doi.org/10.1590/S0102-44502001000300007. Acesso em: 30 jan. 2021.

MARQUES, R. R.; OLIVEIRA, J. S. A normatização de artigos acadêmicos em Libras e sua relevância como instrumento de constituição de corpus de referência para tradutores. 2012. Disponível em:

http://www.congressotils.com.br/anais/anais/tils2012_metodologias_traducao_marquesoliveir a.pdf. Acesso em: 11 mar. 2021.

MILLER, C. R. Estudos sobre: gênero textual, agência e tecnologia. Recife: Editora Universitária da UFPE, 2009.

OWEN, M. The Scientific Article in the Age of Digitization. Amsterdam, University of Amsterdam, 2005.

PACKER, A. L. Os periódicos brasileiros e a comunicação da pesquisa nacional. Rev. USP, São Paulo, n. 89, 2011. Disponível em:

http://rusp.scielo.br/scielo.php?script=sci_arttext\&pid=S0103-

99892011000200004\&lng=en\&nrm=iso. Acesso em 01 junho de 2021.

QUADROS, R. M. Libras. São Paulo: Parábola, 2019.

QUADROS, R. M.; KARNOPP, L. B. Língua de sinais brasileira: estudos linguísticos. Porto Alegre: Artmed, 2004.

SILVA, R. C. da. Gêneros emergentes em Libras da esfera acadêmica: a prova como foco de análise. 2019. 241 f. Tese (Doutorado em Linguística) - Programa de Pós-Graduação em Linguística, Universidade Federal de Santa Catarina, Florianópolis, 2019. Disponível em https://repositorio.ufsc.br/handle/123456789/214869. Acesso em: 30 jan. 2021. 


\section{Sobre os autores}

Lucas Pazoline da Silva Ferreira (Orcid iD: https://orcid.org/0000-0002-0377-5886) Doutor em Letras (Estudos Linguísticos) pela Universidade Federal de Pernambuco (UFPE); mestre em Letras (Estudos Linguísticos) pela Universidade Federal de Sergipe (UFS); especialista em Língua Portuguesa e Literatura pela Faculdade São Luís de França (FSLF) e graduado em Letras-Português pela UFS. Realizou estágio doutoral na Université de Paris VIII (França).

Lorena Gomes Freitas de Castro (Orcid iD: https://orcid.org/0000-0001-8833-6796) Doutoranda no Programa de Pós-Graduação em Letras (Estudos Linguísticos) da Universidade Federal de Sergipe (UFS); mestra em Letras (Estudos Linguísticos) pela mesma instituição; especialista em Tradução e Interpretação em Língua Brasileira de Sinais pela Faculdade Jardins (FAJAR) e graduada em Letras-Português pela UFS.

Recebido em junho de 2021.

Aprovado em novembro de 2021. 


\section{Anexo}

Tradução adaptada e resumida das normas da RBVR

\begin{tabular}{|c|c|c|}
\hline Domínio & $\begin{array}{l}\text { Norma de } \\
\text { publicação }\end{array}$ & Descrição \\
\hline \multirow[t]{4}{*}{$\begin{array}{l}\text { Apresentação } \\
\text { Geral }\end{array}$} & Apresentação & $\begin{array}{l}\text { A Revista Brasileira de Vídeo-Registro em Libras é uma iniciativa do grupo de pesquisa de vídeo-registro, } \\
\text { da UFSC, que busca equilibrar a importância das línguas faladas e sinalizadas através de registros } \\
\text { oficiais/formais e desenvolvimento constante de normas para a publicação em LIBRAS no âmbito } \\
\text { acadêmico. }\end{array}$ \\
\hline & Sobre o artigo & $\begin{array}{l}\text { Um artigo em Libras é um texto científico sinalizado pelo autor ou intérprete autorizado, cuja publicação } \\
\text { possa vir acompanhada por uma versão em texto escrito. }\end{array}$ \\
\hline & Estrutura do artigo & $\begin{array}{l}\text { Primeiramente, identifica-se o autor, seu nome digitado e sinal, inclui-se também a identificação do } \\
\text { intérprete (serviço terceirizado). Essas informações também devem ser sinalizadas. Em seguida, serão } \\
\text { sinalizadas a introdução, o desenvolvimento, as conclusões e as referências. O vídeo deve ser gravado em } \\
\text { formato AVI ou MP4, armazenado em nuvem, e submetido para avaliação através do envio do link para o } \\
\text { e-mail vrlibras@gmail.com. }\end{array}$ \\
\hline & Duração & A comissão aceita artigos que tenham duração de $20 \mathrm{~min}$ a $40 \mathrm{~min}$. \\
\hline \multirow[t]{4}{*}{ Gravação } & Fundo e iluminação & $\begin{array}{l}\text { O fundo do vídeo precisa ser branco e limpo, sem nada. A iluminação não pode estar muito escura, nem } \\
\text { muito clara. É preciso equilíbrio para boa visualização. }\end{array}$ \\
\hline & $\begin{array}{l}\text { Imagem do } \\
\text { sinalizante }\end{array}$ & $\begin{array}{l}\text { A imagem do sinalizante deve ser a mais simples possível, através de roupas lisas de cor única, face limpa, } \\
\text { cabelos presos e acessórios que não inviabilizem uma leitura clara. }\end{array}$ \\
\hline & Vestuário & $\begin{array}{l}\text { Para elaborar o artigo em Libras, orientamos o uso de blusas de cor única e lisas. Como sugestão, pessoas } \\
\text { brancas devem usar camisa azul para títulos, subtítulos, seções e subseções, camisa preta para texto longo } \\
\text { e camisa vermelha para citações; e pessoas negras devem usar camisa azul para títulos, subtítulos, seções } \\
\text { e subseções, camisa cinza para texto longo e camisa vermelha para citaçôes. A cor da camisa pode variar } \\
\text { de acordo com o tom de pele da pessoa que estiver sinalizando. O principal e mais importante é o contraste } \\
\text { que vai contribuir para uma melhor visualização do texto sinalizado. }\end{array}$ \\
\hline & Posição e filmagem & $\begin{array}{l}\text { Para a filmagem, utilizar a câmera fixa em suporte, com configuração de tela 16:9 (widescreen), e } \\
\text { resolução Full HD 1920x1080 ou HD 1080x720, } 29 \text { fps (quadros por segundo). Sobre o posicionamento } \\
\text { do sinalizante, deixar um espaço acima da cabeça e um espaço em que sua postura e sinalização se } \\
\text { encaixem no quadrante de tela 16:9. }\end{array}$ \\
\hline \multirow[t]{4}{*}{$\begin{array}{l}\text { Conteúdo } \\
\text { introdutório }\end{array}$} & $\begin{array}{l}\text { Título, autor } e \\
\text { tradutor }\end{array}$ & $\begin{array}{l}\text { Para apresentação do título, deve-se fazer o sinal título e, em seguida, sinalizar o título. Para apresentação } \\
\text { do subtítulo, deve-se fazer o sinal subtítulo e, em seguida, sinalizar o subtítulo. Para apresentação do } \\
\text { sinalizante (intérprete e/ou autor), deve fazer o sinal próprio, em seguida, sinalizar o nome e o e-mail. } \\
\text { Todas essas informações também devem constar na tela. }\end{array}$ \\
\hline & Resumo & $\begin{array}{l}\text { O resumo deve ter duração de } 1 \min 30 \text { s até } 3 \text { min. A estrutura do resumo sinalizado deve conter objetivo, } \\
\text { fundamentação, metodologia, resultados e discussões, e, por último, as considerações finais. A cor da } \\
\text { camisa ao sinalizar o termo "resumo" é azul independentemente do seu tom de pele. Em seguida, inicia- } \\
\text { se o texto longo, conforme orientação de vestimenta. Por fim, procede-se, ao final do resumo, um sinal de } \\
\text { "finalização" na altura do umbigo. }\end{array}$ \\
\hline & Principais sinais & $\begin{array}{l}\text { Após encerrar o resumo (postura finalização de texto), deve-se sinalizar "sinais + principal" e entre três e } \\
\text { cinco sinais (palavras-chave), vestido com blusa azul independentemente do seu tom de pele. Em seguida, } \\
\text { inicia-se o texto longo, conforme orientação de vestimenta. }\end{array}$ \\
\hline & Abstract & $\begin{array}{l}\text { Abstract é a tradução do resumo e sinais principais (palavras-chave) em Libras para uma língua estrangeira } \\
\text { sinalizada ou escrita. Caso seja apresentado em outra língua de sinais, deve ser apresentado da seguinte } \\
\text { forma: sinal "resumo" + sinal "língua estrangeira" e texto longo, vestido com blusa azul } \\
\text { independentemente do seu tom de pele. Em seguida, inicia-se o texto longo, conforme orientação de } \\
\text { vestimenta. }\end{array}$ \\
\hline $\begin{array}{l}\text { Conteúdo } \\
\text { Central }\end{array}$ & Introdução & $\begin{array}{l}\text { A apresentação do tópico "Introdução" se dá com o sinal de introdução pelo sinalizante vestido com blusa } \\
\text { azul independentemente do seu tom de pele. Em seguida, inicia-se o texto longo, conforme orientação de } \\
\text { vestimenta. Ao encerrar o texto, o sinalizante faz uma postura de finalização textual, seguido do } \\
\text { corte/edição para próxima seção. }\end{array}$ \\
\hline
\end{tabular}




\begin{tabular}{|c|c|c|}
\hline & Desenvolvimento & $\begin{array}{l}\text { A apresentação do tópico "Desenvolvimento" ( } c f \text {. teoria, metodologia e resultados) se dá com um sinal de } \\
\text { entrada de tópico pelo sinalizante vestido com blusa azul independentemente do seu tom de pele. Em } \\
\text { seguida, inicia-se o texto longo, conforme orientação de vestimenta. }\end{array}$ \\
\hline & Conclusão & $\begin{array}{l}\text { A apresentação do tópico "Conclusão" se dá com um sinal de conclusão pelo sinalizante vestido com blusa } \\
\text { azul independentemente do seu tom de pele. Em seguida, inicia-se o texto longo, conforme orientação de } \\
\text { vestimenta. Encerrada a sinalização, escurece a imagem na transição e segue para próxima seção. }\end{array}$ \\
\hline \multirow[t]{3}{*}{$\begin{array}{l}\text { Notas } \\
\text { referências }\end{array}$} & Notas de rodapé & $\begin{array}{l}\text { Para indicar notas de rodapé, sinalize o texto normalmente e use o sinal "nota de rodapé" + "numeração" } \\
\text { (exemplo, } 1,2 \text { etc.) e siga com o texto longo, sinalizando outras notas se for preciso, vestido com blusa } \\
\text { azul independentemente do seu tom de pele. Em seguida, inicia-se o texto longo, conforme orientação de } \\
\text { vestimenta. Encerrada a sinalização, escurece-se a imagem na transição e segue para o texto principal. }\end{array}$ \\
\hline & Referências & $\begin{array}{l}\text { Para as referências bibliográficas, segue-se a NBR } 6023 / \mathrm{ABNT} \text {, as referências sempre estarão de acordo } \\
\text { com ela e por isso são inseridas em língua portuguesa (fundo branco com letras pretas ou vice-versa). Para } \\
\text { indicar as referências bibliográficas, deve-se usar camisa azul para sinalizar o termo "referências } \\
\text { bibliográficas". Depois da transição, ao escurecer a tela, entra o texto em língua portuguesa. }\end{array}$ \\
\hline & $\begin{array}{l}\text { Legendas breves e } \\
\text { fixas }\end{array}$ & $\begin{array}{l}\text { Legendas breves e legendas fixas em tela devem ser escritas em fonte Arial com tamanho legível, } \\
\text { preferencialmente em cor amarela com contorno preto ou letras pretas em caixa alta. A cor pode ser } \\
\text { alterada em relação ao contraste com o fundo. }\end{array}$ \\
\hline \multirow[t]{2}{*}{ Ilustração } & Tabelas e imagens & $\begin{array}{l}\text { Imagens, tabelas ou outros materiais visuais devem ser apresentados um elemento por vez. Deve-se } \\
\text { sinalizar o tipo de material com a respectiva numeração, acrescentando a indicação em português. Se o } \\
\text { material foi copiado de outro lugar, é preciso indicar a fonte logo abaixo. }\end{array}$ \\
\hline & Soletração & $\begin{array}{l}\text { Ao invés das legendas, este recurso também pode ser utilizado quando for preciso indicar nomes diversos, } \\
\text { ano de publicação, número de página, entre outros. Orientamos que evitem sinalizar muito rápido e com a } \\
\text { mão na frente e na altura do rosto. }\end{array}$ \\
\hline \multirow[t]{6}{*}{ Citação } & Formas de citação & Citações podem ser utilizadas em texto escrito na língua original ou em Libras, uma por vez na tela. \\
\hline & Sobre a citação & $\begin{array}{l}\text { Na citação para o vídeo, deve-se sinalizar e apresentar na tela o nome do autor, o ano de publicação e } \\
\text { número de página do texto citado. }\end{array}$ \\
\hline & Citação direta & $\begin{array}{l}\text { Citação direta é uma porção do texto que é trazida de forma literal. Se for citação de material } \\
\text { videossinalizado, pode-se utilizar o trecho do vídeo ou o sinalizante assimila de forma idêntica a citação, } \\
\text { apresentando nome do sinalizante, ano e o intervalo de tempo em que o texto foi sinalizado originalmente. }\end{array}$ \\
\hline & Citação indireta & $\begin{array}{l}\text { Citação indireta é uma porção do texto que é trazida sob a percepção do leitor. Se for citação de material } \\
\text { videossinalizado, pode-se contextualizar de acordo com o texto original e o que se quer dizer, apresentando } \\
\text { nome do sinalizante, ano e o intervalo de tempo em que o texto foi sinalizado originalmente. Para este tipo } \\
\text { de citação, segue-se a vestimenta: camisa preta para pessoas brancas e camisa cinza para pessoas negras. }\end{array}$ \\
\hline & Citação traduzida & $\begin{array}{l}\text { Citação traduzida é a tradução para Libras de um texto escrito, apresentando o nome do autor, o ano e o } \\
\text { número da página do texto original. Se o vídeo assistido foi em ASL (American Sign Language), deve-se } \\
\text { seguir a tradução para a Libras com manutenção dos sentidos, apresentando o nome do sinalizante, o ano } \\
\text { e o intervalo de tempo da duração do trecho utilizado como citação no vídeo mencionado. }\end{array}$ \\
\hline & Citação de citação & $\begin{array}{l}\text { Citação de citação ocorre quando não se tem acesso ao material original. Ela pode se configurar como } \\
\text { citação direta ou citação indireta, porém precisa apresentar nome de autor, ano, número de página da } \\
\text { citação antiga, o termo "apud", nome da obra atual juntamente com o nome do autor, ano e número de } \\
\text { página. }\end{array}$ \\
\hline
\end{tabular}

Fonte: elaborado pelos autores. 